\title{
6. Life at the Femtosecond
}

\author{
Geoffrey C. Bowker
}

\begin{abstract}
This chapter argues that we are creating a fundamental new ontological layer which has far reaching social and political consequences. In this new "present," we need to account for ever higher time frequencies-since this is where decisions are being made which affect us all. In particular it argues that whereas the prior forms of capitalism concentrated on colonizing space, newer forms involve colonizing time.
\end{abstract}

Keywords: computer time, ontology, science studies, temporality, acceleration

Par la vitesse, le présent se transforme en éternité.

-François Hartog ${ }^{1}$

Time, loosely put, is the direction in which physics tells its best stories.

-Craig Callender ${ }^{2}$

And so, Ladies and Gentleman, as the Southwestern train of time is delayed by the points failure of predictability and the pissed off Poole-based passenger of perpetuity becomes trapped in the out-of-order train toilet of eternity, I notice it's the end of the show. -Jack Dee ${ }^{3}$

It is a well-trodden historical path to take Charles Babbage, through his design for an Analytical Engine, as the progenitor of the modern digital computer. This hindsight can make it harder to see an origin of computing in the production of machinery - the Engine was to be a vast machine, deploying techniques learned in his tour of machinery and manufactures

Volmar, A. and K. Stine (eds.), Media Infrastructures and the Politics of Digital Time: Essays on Hardwired Temporalities. Amsterdam: Amsterdam University Press, 2021 DOI 10.5117/9789463727426_CHo6 
in England in the 1820 s (weaving and watch production) in the heat of the industrial revolution and expressed not in binary code but in a symbolic language describing the functioning of machines. ${ }^{4} \mathrm{He}$ conceived it not only in terms of the time compression we associate with computing, but rather its opposite: "It is impossible to construct machinery occupying unlimited space but it is possible to construct finite machinery, and to use it through unlimited time. It is this substitution of the infinity of time for the infinity of space which I have made use of, to limit the size of the engine and yet to retain its unlimited power." 5 This infinite logical time was also-as this new language and as his analysis of time taken for operations in watch production in the 1820 - complemented by time compression: the ineluctable drive to make things happen faster and faster: "whenever the Analytical Engine should exist, all the developments of formula would be directed by this condition - that the machine should be able to compute their numerical value in the shortest possible time." ${ }^{6}$

Babbage's new technology, then, ushered in its own infinite time at the very moment when geology in the 1830 s invented a new infinity of time ${ }^{7}$-a consonance of which Babbage was deeply aware: variations in time scale from the fleeting life of the mayfly to the eons of geology were central to his imaginary. ${ }^{8}$ One of the tricks of the trade for digital computers is to collapse potentially infinite serial time through synchronization: running many operations at the same time and coordinating the results. ${ }^{9}$ Commands to go parallel, spawn processes, and sync results sit on top of the underlying serial structure. ${ }^{10}$ An extreme formulation of the substitution of space for time here is David Deutsch's description of quantum computing as a way of allowing tasks to be performed collaboratively across multiple universes ${ }^{11}$ - he reckoned that to factor a 250 digit number we would need to deploy $10^{500}$ different universes (the operation would run parallel in each, and the result would be given by interference) in almost no time-where Donald Knuth had estimated that it would take over a million years using a million computers. Time was for Deutsch a budgeting issue:

Evolution would never have got off the ground if the task of rendering certain properties of the earliest, simplest habitats had not been tractable (that is, computable in a reasonable time) using readily available molecules as computers. ... What computations, in other words, are practical under a given time and under a given budget? ${ }^{12}$

The parallelism of computing today - whether based in the cloud or under the hood of a PC in the form of multicore processors - trades between two 
temporalities, the speed of messaging (spatial) and the remorseless ticking of the computer clock (temporal; not highly scalable above current limits).

The fastest computers now can do about 16 petaflops (floating point operations) per second - that is 16 by $10^{15}$ operations. That is a whole lotta flops, even for an industry that romances the decimal point. ${ }^{13}$ It means that in fewer than one hundred seconds, it could do the equivalent of one calculation per second since the putative Big Bang. Roughly. On the other hand, in a deeply meaningless calculation, it has been asserted that the human brain performs between 10 and 30 times as many. ${ }^{14}$ The reason why this comparison is even a question is that the holy grail of artificial intelligence needed to replicate the work of many complex professions, such as scientist and psychiatrist-known as AI-complete programs-require complete emulation of the human brain in the interests of efficiency. ${ }^{15}$ If we succeed: "then it will become feasible for machines to carry out such jobs, and to do so more cheaply and more effectively than humans." ${ }^{\text {"6 }}$ Indeed: "if and when human-level AI is achieved, superintelligence will soon follow.... Even if human-level AI is achieved by the most conservative means-by slavishly copying nature - the resulting liberation from the speed restrictions inherent in biology is enough." The romance does not stop there-Murray Shanahan fantasizes: "A theoretically perfect computer with a mass of $1 \mathrm{~kg}$ and occupying a volume of 1 liter would perform $5.4 \times 10^{50}$ logical operations per second on $10^{31}$ bits." This is 39 orders of magnitude greater than today's computers. In the future, we might see a portion of space, as Shanahan quotes Hans Moravec, "rapidly transformed into a cyberspace, [wherein beings] establish, extend, and defend identities as patterns of information flow ... becoming finally a bubble of Mind expanding at near lightspeed."'17

We do not generally think of these kinds of speeds-our lives seem to flow at the rate of less than one thought per second and connectivity for many is so fast that it's basically just instantaneous, and so invisible. (The days of watching an email message unfurl painstakingly over a modem attached to a telephone line are long over.) And yet they affect us in our daily lives. They can irrupt - in the form, say, of the flash crash of 2010, where trading algorithms were making and changing bets at an astonishing rate, leading to a trillion dollar dive on Wall Street that lasted all of thirty-six minutes. More insidiously, very fast computing times are needed for the forms of machine learning being used by casinos, states, and advertising companies such as Facebook and Google to create the nudge technologies that cosset you along the path of life mostly without your being aware. ${ }^{18}$ Thus, Armin Beverungen and Ann-Christine Lange cite Katherine Hayles on the missing half second between perception (registering an event) 
and consciousness (processing it): “This cost [the delay] ... assumes new importance when cognitive nonconscious technical devices can operate at temporal regimes inaccessible to humans and exploit the missing half-second to their advantage."'19

Timothy Mitchell asserts that we are pillaging the past of its biological productions; he estimates that a single liter of petrol needs about 25 metric tons of ancient marine life, and that we burn 400 years of entire plant and animal life production a year. ${ }^{20}$ In our brave new age, we are also burning time at an ever faster rate - and this is just as ontologically, politically, and socially significant. Ian Osborne and Daniel Clery observed in 2004 that the "most important commodity" today is time. ${ }^{21}$ And the control of events at the very small scale is becoming central —as Paul Hegarty argues in his discussion with Gary Genosko of Google's attempt to "own" the smear of the leap second needed to cope with the irregularities of the earth (that perfect clock for the Enlightenment scientists): "Google's execution of time-critical processes establishes its mastery over the measurement and manipulation of humanly imperceptible micro-temporal events. ${ }^{\prime 22}$ And it all adds up - by one estimate, the world will have spent a billion years online in $2018 .^{23} \mathrm{As}$ Wolfgang Ernst says, we need to take machine time seriously. ${ }^{24}$

The argument here will be twofold: first that we are creating new ontological layers of the socionatural through the development of computing technology and second that the associated temporalities are richly textured, that is, not all about speed.

\section{Speed, Acceleration and Delay}

High-frequency trading is always a good spot to find computers and networks working at their fastest. A network switch made by Metamako "allows a trade order to be placed in the time it takes a photon to travel 90 feet" ${ }^{25}$ - and there is a market, these switches in 2016 were selling at 100 units a month. We need shorter times. This can reach fantasy proportions: "When in 2012 scientists briefly thought they'd detected neutrinos that could travel faster than light, for example, high-frequency traders pondered how they might build a system that would execute trades that would, theoretically, occur in the past." ${ }^{26}$ In this current imaginary, it really is only a step from high energy physics and cosmology (two modes of inquiry exploring the nature of physical reality) and computing: ${ }^{27}$ a short circuit revealing of the ontological significance of computer time- "If you understand the universe as a giant computer constantly calculating its way through time, it's always easier-less 
resource-intensive-for things to flow forward (cause, then effect) than backward (effect, then cause). This idea is called the "arrow of time." ${ }^{28}$ As Sybille Krämer says, time moves in this imaginary from being "a universal form of our perception or existence" to "a universal form of technological accessibility."29

Even without tachyons to help, the "light cone" ${ }^{30}$ of events in computing can seem to violate causality. In Flash Boys, Michael Lewis describes an interesting move that high-frequency traders in dark pools made. Brad Katsuyama from the Royal Bank of Canada was wondering why when he put in a "buy" order, the shares he wanted to buy (which were listed) evaporated before he could complete the trade-even though he saw the price and the offer in "real time." It gets baroque, but it turns out the reason was that there were several different places to do trades clustered around NY and New Jersey, and some folks had learned how to manipulate millisecond differences in trading in such a way that offers and prices were manipulated before his orders went through. So he wrote an algorithm that deliberately slowed his messages to some of the trading centers so that all his messages arrived at each of the centers at the same time. This produced a realignment between the "ticker tape" prices and offers and his trades. So the ticker tape (central to the temporality of the market since the nineteenth century) ${ }^{31}$ did not show anything real until the delays were brought in — a real "live" market could only be produced in this way. ${ }^{32}$ The role of delay at very high speeds in order to create the appearance of real-time is central to Kittler's canonical essay on time-axis manipulation-he observes that there is no "real-time" analysis, delay is needed in order to assemble the parts ("only that which is switchable is at all") to give the impression of events passing in real time. ${ }^{33}$ This new reality is only buildable because "time exists as quantified and synchronized packets whose size approaches zero." ${ }^{34}$ As Espen Ytreberg remarks in the context of the production of live events on television, the present is an outcome of the manipulation of display. ${ }^{35}$

These time-manipulations, at speeds far surpassing human perception, are real in their consequences: fortunes are lost and won; real-time events are created on television sets. And as David Mills asserts, "Reliable and accurate computer time is necessary for any real-time distributed computer application, which is what much of our public infrastructure has become." ${ }^{36}$ What of the human in this? Well, for one thing, the micro-temporality of the computer can only be supported through the macro-temporality of constant care. ${ }^{37}$ Humans have been in the loop since the earliest days of computing - Babbage envisaged needing them for logarithmic functions (when the machine needed a log function it would ring a bell; if the attendant 
brought the wrong card containing the function, it would just ring louder). ${ }^{3}$ Beverungen and Lange discuss a high-frequency trader matching his circadian rhythm to the cadences of his algorithms - the futures market he traded in was open 23 hours a day; he only slept four hours a night and even then got up every 45 minutes to tend his flock of "algos" (they were pre-programmed to rewrite themselves and interact in complex ways, so one could never be sure what decisions they were making). 39

Where game theoretic economists gave us homo economicus (the person making "rational" choices defined by self-interest), one dream now is of machina economicus, where algorithms working at the speed of light could make rational choices for us ${ }^{40}$; tellingly Parkes and Wellman anoint this "a new species of machine. ${ }^{n 11} \mathrm{~A}$ recent textbook on Blockchain (the technology behind Bitcoin) promulgated the vision that we would need to delegate more than our rational qualities to machines, but also our ethics and our policy; the future would see "a public open distributed ledger with general purpose rational agents (Machina Economicus) running on blockchain, making decisions and interacting with other intelligent autonomous agents on behalf of humans and regulated by code instead of law or paper contracts," and the new technology would "impact every industry including but not limited to finance, government, and media. ${ }^{122}$ By this vision, there would be a whole level of life going on at speeds far exceeding any possible human perception:

One solution might be to introduce intelligent bots or AAs [autonomous agents] or even contracts that are programmed with regulatory logic embedded within them. They are most likely programmed by regulators and law enforcement agencies and live on the blockchain as a means to provide governance and control. 43

The coinage "live" is interesting here; for they will certainly have to be autonomous and adaptive - the comforting myth of their being programmed by humans as unreal as in the case of high-frequency trading: if this were to come to pass, they would need to be designed by algorithms to evolve by circumstance. Larry Lessig, who went from being a contract lawyer to writing about code as law, would surely recognize this world. ${ }^{44}$ In general, it has been claimed, human knowledge and cognition are progressively more marginal in markets. ${ }^{45}$

Where is the real in all this? It is certainly the case that staggering resources are being put into making computers (and the algorithms they spawn) faster. Equally certain, new kinds of events are occurring in the world spawned by new kinds of entities which act using much the same register 
as we have ascribed to intentional agents in the past. If we take ontology as being about what kinds of things the world is peopled with, there are indeed new kinds of entities, operating at new times.

Just as evolutionary theory looks very different if taken at the temporality of the virus or the human (even current attempts to find selection within one human generation - such as lactose tolerance-are necessarily concerned with multiple years ${ }^{46}$ ); so does history look very different if taken at the temporality of these new entities. ${ }^{47}$ The real question is whether it is just the world inside the computer, or if something very different is going on at this new ontological level—will we find, as Jacques Revel observed in the context of microhistory over short time scales, that "the change in the scale of observation revealed not just familiar objects in miniature but different configurations of the social. ${ }^{248}$

\section{Linear Time}

The formal structure of time in a computer is relatively simple: it all comes down to carrying out one instruction per tick of the clock (I am not covering here modifications which partially work around this; they do not make an analytic difference) - the faster the clock ticks, the faster the computer performs. The trouble is that clocks can only tick so fast:

For many years, we could count on processor clock speeds increasing at a steady rate. Physical limitations present a fundamental roadblock to ever-increasing clock speeds, however: because power density increases superlinearly with clock speed, chips run the risk of melting once their clock speeds become high enough. In order to perform more computations per second, therefore, chips are being designed to contain not just one but several processing "cores."49

As we have seen, it really is serial despite the language of parallelism. In a process which might be called descentralization, each set of commands in parallel processing can be converted into a serial set (one darned thing after another):

the memory behaves as if the instructions were executed sequentially according to some global linear order that preserves the individual orders in which each processor issues its own instructions. For dynamic multithreaded computations, which are scheduled onto processors 
automatically by the concurrency platform, the shared memory behaves as if the multithreaded computation's instructions were interleaved to produce a linear order..$^{\circ}$

It is hard work maintaining this remorseless linearity-both the Therac-25 radiation therapy deaths ${ }^{51}$ and the North American Blackout of 2003 were caused by so-called race conditions. These are when time gets out of joint and a new value is posted to a variable when the old value was still needed: "A determinacy race occurs when two logically parallel instructions access the same memory location and at least one of the instructions performs a write." ${ }^{2}$ The difficulty arises because most of the time the program will run well (which makes it very hard to test for), but occasionally the unlikely but logically possible race will occur and prove disastrous. Again, events at the micro level have macro effects.

There is an analogy here with quantum mechanics. At the level of our day-to-day perception (being, as we are, the measure of all things) a Newtonian physics is good enough to go by; at the level of the very small and very fast, it seems as if there is a new set of rules - a different kind of physics. Our generic relationship with computers works pretty well if we assume they work in the same temporality as ours, just scaled down. When it gets interesting is when the nested scaling breaks down-as in a determinacy race-and we need to recognize that time becomes a different thing both sociotechnically (it becomes pure commodity) and socionaturally (it becomes granular, discontinuous - taking on just the property that Kittler hailed as central ${ }^{53}$ ). And the temporalities are consonant-in datestamp format: "The second can be represented to about 500 attoseconds, or about a tenth of the time light takes to pass through an atom." 54 We need that shorter time.

\section{Historical Time}

Computers have come to define new historical epochs - somewhat helter skelter but with a determined drive: "With the invention of bitcoin in 2008 the world was introduced to a new concept that is now likely to revolutionize the whole of society. It's something that has promised to impact every industry including but not limited to finance, government, and media."55 Not bad for an algorithm - the mining of bitcoins is now, alas, no longer "democratic" but under the control of large organizations that can afford the suites of graphics cards that can mine most efficiently. 
Within the computer, all kinds of historical time are reproduced. For the Ethereum blockchain algorithm, the oil companies have reappeared, with two key variables being gasPrice and gasLimit. ${ }^{6}$ In his book on computer time synchronization, David Mills revels in the investing of human historical temporality into the computer. He tells of the need to separate "the "truechimers, whose clocks gloriously tell the truth from the falsetickers, whose clocks lie viciously." ${ }^{57}$ These terms are not his florid invention-they are terms of the art in the field of computer time. All the pageantry of human history can be found at the level of the femtosecond:

Even under peacetime conditions, the truechimers surviving the select algorithm might have somewhat different time offsets due to asymmetric delays and network jitter. Various kinds of cluster and combine algorithms have been found useful to deliver the best time from the unruly bunch. The one used in NTP sorts the offsets by a quality metric, then repeatedly discards the outlier with the worst quality until further discards will not reduce the residual error or until a minimum number of servers remain. The final clock adjustment is computed as a weighted average of the survivors..$^{8}$

This war of clock against clock is needed to prevent stocks from being sold before they are bought or the evening news coming on at midnight. ${ }^{99}$ At stake is nothing less than the principle of cause and effect (it is notable how often the troubling of cause and effect comes up in discussions of computing). Thus, in real-time systems, in order to avoid "anomalous behaviors (e.g., by actions that bypass the system's normal operation and could violate the cause-effect relation by "making holes" in the "light cone" of events, the interactions between the system and the environment must be explicitly take into account." ${ }^{60}$ For Mills, the internet is a growing child, with its development measured in its need for and colonization of ever shorter time intervals—100 microseconds when it was "teething" to a few microseconds in its current "adolescent" state.$^{61}$ He looks forward to the glorious rule, pace E. P. Thompson, of time, work-discipline, and postindustrial capitalism: "The ultimate accuracy can be achieved only when the clock can be disciplined with exquisitely intimate means. In practice, this requires the discipline algorithm, normally implemented in the NTP software, to be implemented in the operating system kernel." Just as we have been disciplined over the past few hundred years out of lives lived by diurnal and seasonal rhythms into lives run on schedule, by calendar, so have our computers undergone their own temporal discipline over the past thirty years. 
We have seen the importance of voting models. It need not be about industrial discipline under democratic values, though. Professor of Cognitive Robotics Murray Shanahan reckons that in superintelligent (meaning beyond human intelligence) AI might become a "willing intellectual slave who never eats or sleeps and wants nothing more than to work" and that this would be "many corporations' idea of the perfect employee, especially if they don't require wages. ${ }^{n 2}$ He does wonder, though, whether they could be treated as slaves with "moral impunity." ${ }^{3}$ In turn, self-reproducing superintelligent machines could "colonize the galaxy." ${ }^{64}$ One popular methodology is the imperialist competitive algorithm, which models "social evolution." ${ }^{\text {" }}$ It involves assimilating colonies, the occasional revolution, and of course intense warfare between empires. So former economic orders don't go away, they get buried in machines operating in temporalities humans cannot directly access. There is an analogy here with the kind of historicity explored by Kathleen Davis. ${ }^{66}$ She points to the cocreation of slavery and colonial power (extended in space) and the myth of the middle ages and feudal order (extended back in time). The computer spawns multiple historical times which we thought were over (ontogeny recapitulating phylogeny). ${ }^{67}$

There is a trope in the history of science that Copernicus left us with an earth occupying no privileged position in the universe, Darwin left humans with no privileged position in time, and Freud left reason with no privileged position in the mind. As early as 1985 , Michael Arbib argued that the computer left humans with no privileged position in society. ${ }^{68}$ Shanahan leaves us with no privileged position in history, arguing that, possibly, real history is about the history of matter gaining complexity. ${ }^{69}$ His position is reminiscent of Sybille Krämer's whether this disappearance of humans from the story was "the intellectual property of a media-technological version of eschatology."70 From this decentered position, it makes a sort of sense that we project onto matter-with a far greater temporal range than our own-the course of (non)human history.

\section{Present (Future/Past)}

Much writing about computers inhabits the future tense-it's as pervasive as the passive voice of policy documents. Babbage concluded of his Analytical Engine in $185^{2}$ that "nothing but teaching the engine to foresee and then to act on that foresight could lead me to the object I desired." ${ }^{11}$

Prediction has been core to the development of computing in the twenty-first century. It often works on a form of neutral hypothesis-it is easiest 
if one assumes that the future is like the present: we are constantly "updating to remain the same," in Wendy Chun's lovely locution, ${ }^{72}$ because the power of, say, recommender systems is to make us cleave to our present profile in the future. The work of a "discriminant" in machine learning (such as credit risk) is based on the assertion that "the future is like the present."73 We are creating a new "temporeality." 74

The colonization of the future by the present is a theme explored by Hartog historiographically: "The present became something immense, invasive, and omnipresent, blocking out any other viewpoint, fabricating on a daily basis the past and the future it needed." ${ }^{75} \mathrm{He}$ ties it to a shift away from the future being seen as holding promise (as in the Victorian age of certaint $y^{76}$ or the French revolutionary fervor for a better society) to the future as being one of threat and risk (environmental degradation, biodiversity loss, and so forth). A common trope in computing holds similar fears. Sometime in the next twenty to forty years, the world as we know it will change radically and frequently not for the better-it depends on how you understand the coming "singularity." Is it a nightmare or an optimistic vision to pose the following: "Between 2020 and 2050: Artificially Intelligent DAOs [distributed autonomous organizations] will prevail on blockchains that will make rational decisions on behalf of humans"?77 It is certainly a world in which "humans have become increasingly irrelevant." ${ }^{78}$

Jürgen Schmidhuber, who sees full artificial intelligence as a simple function of whether or not we can compress time into small enough units in the computer, takes a trope that was created by Ray Kurzweil and recently developed by Geoffrey West. ${ }^{79}$ Counting down from the omega point, he argues that we have witnessed (for West, we require) ever faster rates of breakthrough in modes of life-starting from humans leaving Africa at $2^{9}$ lifetimes, we advance, step by logarithmic step, down to the Greeks inventing democracy and science at $2^{5}$ lifetimes, the Age of Enlightenment at $2^{2}$ lifetimes, PCs at half a lifetime, and the upcoming revolution projected to occur in a quarter of a lifetime. ${ }^{80}$ (Schmidhuber is somewhat tongue-in-cheek here-he does wonder at the end of the paper whether this compelling scale is more a feature of the way we remember-giving more weight to recency - than of the nature of the record.) In this vision we need deal only with ever-shorter futures until the future disappears through machine learning into the unchanging, untheorized singularity.

Similarly, there the past is colonized by the present to the point of disappearance. We can see this through the language of the Internet of Things. Pioneering cybernetician W. Ross Ashby asserted in the 1950s that a well-configured cybernetic system did not need to hold its own memory. 
The world, and the machines used to analyze it, could be constructed in terms of closed Markov chains - meaning that all one ever needed to know to understand the state of either world or machine was to know its present state and the set of rules for its change. Remembering what a former state had been was simply irrelevant. This has been a major temporal metaphor since the Enlightenment - for Laplace, the universe could be uniquely described by a set of first-order differential equations, meaning that knowing the state of the world right now meant that you could predict its future state to any degree of required accuracy.

As Ashby developed his work especially in Design for a Brain, ${ }^{81}$ he made much of a theory of interchangeability, whereby contingent history just did not matter - the past was irrelevant. We might "lose" Hampshire to a devastating accident, but the Britain would auto-regulate and keep functioning in the future pretty much as in the past-Britain was a system with interchangeable parts. Similarly, the death of an individual human just did not mean much in terms of the temporality of the system. Humans are interchangeable with each other and with machines- "really" we are just talking about a set of operations carried out in metronomic fashion.

When Neil Gross, a pragmatist sociologist, wrote a piece in 1999 entitled "The Earth Will Don an Electronic Skin" presaging the Internet of Things, he wrote: "Hundreds of thousands of PCs working in concert have already tackled complex computing problems. In the future, some scientists expect spontaneous computer networks to emerge, forming a 'huge digital creature." ${ }^{82}$ His image was of a Leviathan, matching Hobbes' (the famous frontispiece to whose work pictures a colossus made of humans forming the body of the king/state). The PCs are working in concert—-they are synchronized together. He goes on:

It will use the Internet as a scaffold to support and transmit its sensations. This skin is already being stitched together. It consists of millions of embedded electronic measuring devices: thermostats, pressure gauges, pollution detectors, cameras, microphones, glucose sensors, EKGs, electroencephalographs. These will probe and monitor cities and endangered species, the atmosphere, our ships, highways and fleets of trucks, our conversations, our bodies-even our dreams.

This image of the colossus well exceeds human temporal scales-it exists in the eternal present of the responsive machine. It is a fundamentally new fact about human existence that our human temporality is now that of the sociotechnical world we have created. 
There is a whole new ontological level which works at ever small time scales and yet which can have large-scale effects. Humans drop out of the equations in much the same way as objects drop out of the equations of quantum mechanics. They are not quite the self-contained things we used to imagine: for both, we need new sets of rules to study in fine the operation of the world. We have both constructed physically and constituted socially new temporalities and new understandings of objects that just do not work at the rate of human perception.

\section{Conclusion}

Time is at the center of our political economy_displacing space, which was central to colonial power: the demotion of the meter to the distance per second traveled by light $(1 / 299,792,458)$ is but a symptom of this new form. Network time protocol is enforced in "space, on the seabed ... and on every continent, including Antarctica." ${ }^{\prime 3}$

The control of space was the control of other countries in far-flung empires. But it was already about the control of time. When the oil companies came into Venezuela, they were able to interact beneath the state-in the subsurface-manipulating temporalities that had never explicitly been part of Venezuelan economic life. ${ }^{84}$ This knowledge enabled them to help supercharge the metabolism of the human species by tapping into low-entropy stored solar energy and converting it into commodities and waste at a higher entropy. ${ }^{85}$ Computer time is central here: the Schlumberger company was at the fore of the development of expert systems to deal with microtemporalities (reading seismic waves), which revealed the macro structure of the earth. As Paul Prudence says, "Algorithms can become a Rosetta Stone for the lithic scryer, for if the writing of stones are hieroglyphics for Caillois then the language of algorithms is a demotic script that can bridge the gap between geological noise and intelligible information. ${ }^{\text {" } 66}$

Learning to work temporalities outside of our immediate sensory experience has been central to the working of capitalism. Alfred Sohn-Rethel's assertion that Galilean absolute space and time was basically about the free flow of the commodity form in an ideal, frictionless market gains traction in this context. The faster the money-commodity-money cycle, the more surplus value can be created-in other words, the more we can work at higher temporalities, the better for the system.

The remorseless, rapid ticking of the computer clock enables control at a wide range of temporal scales. The rapid ticking of the truechimers is 
a source simultaneously of the speed and acceleration we experience in the present and the extension of the present into the immediate past and future, creating Hartog's "monstrous present." 87 There is no historical time as modelled by historiographers on the one side and computer time on the other. At all temporal scales they interpenetrate. This happens at the scale of the longue durée: the computer grew up with and is modeled on factory production as industrialization took command of world economies (from the pillaging of natural resources by the colonizing powers to the organization of manufacturing hubs in the developed world). The event of the short durée is increasingly mediated by machine learning. And at the very shortest scales - the femtosecond - a variety of historical times play out.

We saw above Revel's assertion that scaling down temporally produced new configurations of the social and the political. ${ }^{88}$ In computer time, even while all of these temporal scales interpenetrate, different configurations are being developed. But they are made of the same stuff as standard historical time. Inside computers, we find colonialism, slavery, resource control, and the manufactured event beloved of media theory-as well as geological and evolutionary time. The technological here is not different from other spheres of existence; it is fully coeval with them.

This can only really make sense if we see that the sociotechnical and the socionatural work together. There is no nature "out there" for the computer - we understand nature through its workings at the same time as we model the computer on that understanding.

Life at the femtosecond is consequential for our ways of being in, apprehending, and acting in the world. Real-time is ineluctably real time, and for us real time is now real-time.

\section{Notes}

1. François Hartog, Régimes d'historicité: Présentisme et experiences (Paris: Seuil, 2003), 120. "Through speed, the present transforms itself into eternity" (my translation).

2. $\quad$ Craig Callender What Makes Time Special (Oxford and New York: Oxford University Press, 2017), 156.

3. I'm Sorry I Haven't a Clue, Season 70, Episode 2.

4. Charles Babbage, "On a Method of Expressing by Signs the Action of Machinery," Philosophical Transactions of the Royal Society of London 116, no. 1-3 (1826), 250-265.

5. Charles Babbage, Passages from the Life of a Philosopher, ed. Martin Campbell-Kelly (New Brunswick, NJ: Rutgers University Press, 1994 [1864]), 94. 
6. Babbage, Passages, 90.

7. See Charles Lyell, The Principles of Geology, vol. 1 (Chicago: University of Chicago Press, 1990 [1830]).

8. Charles Babbage, The Ninth Bridgewater Treatise: A Fragment, 2nd ed. (London: John Murray, 1838).

9. This temporal collapse is perhaps pointed to by Kittler's use of "a screaming comes across the sky" (16) - the opening and closing lines of Gravity's Rainbow, encapsulating the extensive time of the novel into the moment of the dropping of a rocket.

10. Thomas H. Cormen, Charles E. Leiserson, Ronald L. Rivest, and Clifford Stein, Introduction to Algorithms, 3rd ed. (Cambridge, MA: MIT Press, 2009), 774.

11. David Deutsch, The Fabric of Reality (London: Penguin, 1997), 155.

12. Deutsch, Fabric of Reality, 200, 196-7.

13. I borrow this felicitous phrase from Robert F. Service, "Time's Romance of the Decimal Point," Science 306, no. 5700 (November 19, 2004): 1310-1311.

14. AI Impacts, https://aiimpacts.org/brain-performance-in-flops/, accessed November 25, 2019. Kurzweil gives $10^{16}$.

15. "Messy emulation" is just doing neuron-for-neuron mapping; other forms would develop new kinds of intelligence. (It is surprising that such a limited view of the workings of the brain - neuron firing - persists in computer science, as well as the willful ignorance of the distributed, embodied nature of cognition.)

16. Murray Shanahan, The Technological Singularity (Cambridge, MA: MIT Press, 2015), 152-3.

17. Shanahan, Technological Singularity, 157.

18. Dow Schulman, xxx.

19. Armin Beverungen and Ann-Christine Lange, "Cognition in High-Frequency Trading: The Costs of Consciousness and the Limits of Automation," Theory, Culture \& Society 35, no. 6 (2018): 80.

20. Timothy Mitchell, Carbon Democracy: Political Power in the Age of Oil (London: Verso, 2011), 15 .

21. Ian Osborne and Daniel Clery, "Higher Standards," Science 306, no. 5700 (November 19, 2004): 1307.

22. Gary Genosko and Paul Hegarty, "Where Has Become of Time? Temporal Smearing and Media Theory," SemiotiX, https://semioticon.com/semiotix/2018/o3/where-has-become-of-time-temporal-smearing-and-mediatheory/.

23. Simon Kemp, "Digital in 2018: World's Internet Users Pass the 4 Billion Mark," We Are Social, January 20, 2018, https://wearesocial.com/ blog/2018/01/global-digital-report-2018. This is spread over 4 billion users, and interesting more for the order of magnitude rather than as a realistic assessment.

24. Quoted in Jussi Parikka, "Introduction," in Wolfgang Ernst, Digital Memory and the Archive, ed. Jussi Parikka (Minneapolis: University of Minnesota Press, 2014), 15. 
25. Michael Reilly, "High-Frequency Trading is Nearing the Ultimate Speed Limit," MIT Technology Review, August 9, 2016, https://www.technologyreview. com/s/6o2135/high-frequency-trading-is-nearing-the-ultimate-speed-limit/.

26. Reilly, "High-Frequency Trading."

27. See, for example: Rafi Letzter, "How Quantum Computers Could Kill the Arrow of Time," Live Science, July 27, 2018, https://www.livescience. com/63182-quantum-computer-reverse-arrow-time.html.

28. Letzter, "Quantum Computers."

29. Sybille Krämer, "The Cultural Techniques of Time Axis Manipulation: on Friedrich Kittler's Conception of Media," Theory, Culture \& Society, 23, no. 7-8 (2006): 93-109

30. Fabio A. Schreiber, "Is Time a Real Time? An Overview of Time Ontology in Informatics," in Wolfgang A. Halang and Alexander D. Stoyeno (eds.), Real Time Computing, NATO ASI Series, Series F: Computer and Information Systems 127 (1994): 294.

31. Alex Preda, "Socio-technical Agency in Financial Markets: The Case of the Stock Ticker," Social Studies of Science 36, no. 5 (2006): 753-782. Speed has been central to the market since at least the late eighteenth century-Chartier $(\mathrm{xxx})$ points to five issues of a paper being put out daily to describe market changes. We often forget this time compression from pre-digital days-in London in the early nineteenth century there would be four or five postal deliveries a day_making the service more like email than the more recent instantiations we tend to project onto the past (under the retronym "snail mail").

32. Michael Lewis, Flashboys: Cracking the Money Code (London: Allen Lane, Penguin. 2014).

33. Friedrich Kittler, "Real Time Analysis, Time Axis Manipulation," Cultural Politics 13, no. 1 (2017), 1-17.

34. Kittler, "Real Time Analysis," 10.

35. Espen Ytreberg.

36. David L. Mills, Computer Network Time Synchronization: The Network Time Protocol on Earth and in Space, 2nd ed. (Boca Raton, FL: CRC Press, 2016), xxiii.

37. See Gabriele Schabacher in this volume.

38. Babbage, Passages, 90.

39. Beverungen and Lange, "Cognition in High-Frequency Trading," 88-89.

40. Martin Prause, "On the Trail of Machina Economicus," Info Insights, 2017.

41. David C. Parkes and Michael P. Wellman, "Economic Reasoning and Artificial Intelligence," Science 349, no. 6245 (July 17, 2015): 267-272. doi:10.1126/ science.aaa8403.

42. Imran Bashir, Mastering Blockchain: Distributed Ledgers Decentralization and Smart Contracts Explained (Birmingham-Mumbai: Packt, 2018), 1.

43. Bashir, Mastering Blockchain, 475 .

44. Lawrence Lessig, "Law regulating code regulating law," Loyola University Chicago Law Journal 35 (2003): 1-14.

45. Beverungen and Lange, "Cognition in High-Frequency Trading," 80. 
46. Elizabeth Pennisi, "Humans Are Still Evolving-And We Can Watch It Happen," Science, May 17, 2016, https://www.sciencemag.org/news/2016/05/ humans-are-still-evolving-and-we-can-watch-it-happen.

47. Thanks to Bodhisattva Chattopadhyay for this observation. See Bodhisattva Chattopadhyay and Geoffrey C. Bowker, "Ant Network Theory," NatureCulture 5 (2019): 26-49.

48. Jacques Revel, introduction to Histories: French Constructions of the Past, ed. Jacques Revel and Lynn Hunt, trans. Arthur Goldhammer (New York: New Press, 1995), 46.

49. Cormen et al., Introduction to Algorithms, 10.

50. Cormen et al., Introduction to Algorithms, 779.

51. Nancy G. Leveson and Clark S. Turner, "An Investigation of the Therac-25 Accidents," Computer 26, no. 7 (1993): 18-41.

52. Cormen et al., Introduction to Algorithms, 788.

53. Kittler, Discourse Networks 1800 / 19oo, trans. Michael Metteer (Stanford, CA: Stanford University Press, 1992).

54. Mills, Computer Network Time Synchronization, 18.

55. Bashir, Mastering Blockchain, 1.

56. Bashir, Mastering Blockchain, 216.

57. Mills, Computer Network Time Synchronization, 7.

58. Mills, Computer Network Time Synchronization, 8.

59. Mills, Computer Network Time Synchronization, 10.

6o. Fabio A. Schreiber, "Is Time a Real Time? An Overview of Time Ontology in Informatics" in Wolfgang A. Halang and Alexander D. Stoyeno (eds.), Real Time Computing, NATO ASI Series, Series F: Computer and Information Systems 127 (1994): 283-307.

294.

61. Schreiber, "Is Time a Real Time?," 9 .

62. Murray Shanahan, The Technological Singularity (Cambridge, MA: MIT

Press, 2015), 93. See E. P. Thompson, "Time, Work-Discipline, and Industrial Capitalism," Past \& Present 38 (1967): 56-97.

63. Shanahan, The Technological Singularity, 153.

64. Shanahan, The Technological Singularity, 157.

65. https://en.wikipedia.org/wiki/Imperialist_competitive_algorithm. Accessed December 21, 2018.

66. Kathleen Davis, Periodization and Sovereignty: How Ideas of Feudalism and Secularization Govern the Politics of Time (Philadelphia: University of Pennsylvania Press, 2008), 42-50.

67. Ernst Haeckel, who was so influential in establishing the tree metaphor for biological descent also gave us the resounding tocsin "ontogeny recapitulates phylogeny." The two are closely linked when taken in terms of information organization and access in computer science terms; and in terms of historiographical analysis in the nineteenth century in humanist terms.

68. Michael A. Arbib, "On Being Human in the Computer Age," in Impacts of Artificial Intelligence, ed. Robert Trappl (Amsterdam: Elsevier, 1985). 
69. Shanahan, The Technological Singularity, xxii-xxiii.

70. Krämer, "The Cultural Techniques of Time Axis Manipulation," 107.

71. Babbage, Passages, 86.

72. Wendy Chun, Updating to Remain the Same (Cambridge, MA: MIT Press, 2016), 79-85.

73. Ethem Alpaydin, Introduction to Machine Learning, 3rd ed. (Cambridge, MA: MIT Press, 2014).

74. Jussi Parikka, “The Underpinning Time: From Digital Memory to Network Microtemporality," in Digital Memory Studies: Media Pasts in Transition, ed. Andrew Hoskins (New York: Routledge, 2018), 156-172.

75. François Hartog, Regimes of Historicity: Presentism and Experiences of Time (New York: Columbia University Press, 2015), 185.

76. Asa Briggs, A Social History of England (New York: Viking, 1984).

77. Bashir, Mastering Blockchain, 475 .

78. Kittler, "Real Time Analysis," 13.

79. Ray Kurzweil, The Singularity Is Near (New York: Penguin, 2005). Geoffrey West, Scale: The Universal Laws of Growth, Innovation, Sustainability, and the Pace of life, in Organisms, Cities, Economies, and Companies (New York: Penguin, 2017).

8o. Jürgen Schmidhuber, "New Millennnium AI and the Convergence of History," ArXiv, June, 29, 2006.

81. W. Ross Ashby, Design for a Brain (London: Chapman \& Hall, 1954).

82. Neil Gross, "The Earth Will Don an Electronic Skin," Bloomberg, August 30, 1999, https://www.bloomberg.com/news/articles/1999-08-29/14-the-earthwill-don-an-electronic-skin.

83. Mills, Computer Network Time Synchronization, 23.

84. Geoffrey C. Bowker, Science on the Run: Information Management and Industrial Geophysics at Schlumberger, 1920-1940 (Cambridge, MA: MIT Press, 1994).

85. Alf Hornborg, "Machine Fetishism, Value, and the Image of Unlimited Good: Towards a Thermodynamics of Imperialism" in Man, New Series, Vol. 27, No. 1 (Mar., 1992), pp. 1-18.

86. Paul Prudence, "The Algorithmic Writing of Stones: A Cybernetics of Geology," SubStance 47, no. 2 (2018): 71-83: 82.

87. I borrow this phrase from Helge Jordheim, personal communication.

88. Revel, Histories, 206.

\section{About the Author}

Geoffrey C. Bowker is Donald Bren Chair at the School of Information and Computer Sciences, University of California at Irvine. Together with Leigh Star he wrote Sorting Things Out: Classification and its Consequences. His most recent book is Memory Practices in the Sciences. 